\title{
Feasibility of community-based screening for cardiovascular disease risk in an ethnic community: the South Asian Cardiovascular Health Assessment and Management Program (SA-CHAMP)
}

Charlotte A Jones ${ }^{1 * \dagger}$, Alykhan Nanji ${ }^{2 \dagger}$, Shefina Mawani ${ }^{3 \dagger}$, Shahnaz Davachi ${ }^{4}$, Leanne Ross ${ }^{2 \dagger}$, Ardene Vollman ${ }^{3 \dagger}$, Sandeep Aggarwal ${ }^{2}$, Kathryn King-Shier ${ }^{5}$ and Norman Campbell ${ }^{1}$

\begin{abstract}
Background: South Asian Canadians experience disproportionately high rates of cardiovascular disease (CVD). The goal of this qualitative study was to determine the feasibility of implementing a sustainable, culturally adapted, community-based CVD risk factor screening program for this population.

Methods: South Asians ( $\geq 45$ years) in Calgary, Alberta underwent opportunistic cardiovascular risk factor screening by lay trained volunteers at local religious facilities. Those with elevated blood pressure (BP) or $\geq 1$ risk factor underwent point of care cholesterol testing, 10-year CVD risk calculation, counseling, and referral to family physicians and local culturally tailored chronic disease management (CDM) programs. Participants were invited for re-screening and were surveyed about health system follow-up, satisfaction with the program and suggestions for improvement. Changes in risk factors from baseline were estimated using McNemar's test (proportions) and paired t-tests (continuous measures).
\end{abstract}

Results: Baseline assessment was completed for 238 participants (median age 64 years, 51\% female). Mean TC, HDL and TC/HDL were $5.41 \mathrm{mmol} / \mathrm{L}, 1.12 \mathrm{mmol} / \mathrm{L}$ and 4.7 , respectively. Mean systolic and diastolic blood pressures $(\mathrm{mmHg})$ were 129 and 75 respectively. Blood pressure and TC/HDL ratios exceeded recommended targets in 36\% and 58\%, respectively, and 76\% were at high risk for CVD. Ninety-nine participants (47\% female) attended rescreening. $82 \%$ had accessed health care providers, 22\% reported medication changes and 3.5\% had attended the CDM programs. While BP remained unchanged, TC and TC/HDL decreased and HDL increased significantly (mean differences: $-0.52 \mathrm{mmol} / \mathrm{L},-1.04$ and $+0.07 \mathrm{mmol} / \mathrm{L}$, respectively). Participants were very satisfied $(80 \%)$ or satisfied (20\%) with the project. Participants suggested screening sessions and CDM programs be more accessible by: delivering evening or weekends programs at more sites, providing transportation, offering multilingual programs/ translation assistance, reducing screening wait times and increasing numbers of project staff.

Conclusions: SA-CHAMP demonstrated the feasibility and value of implementing a lay volunteer-led, culturally adapted, sustainable community-based CVD risk factor screening program in South Asian places of worship in Calgary, Alberta, Canada. Subsequent screening and CDM programs were refined based on the learnings from this study. Further research is needed to determine physician and patient factors associated with uptake of and adherence to risk reduction strategies.

Keywords: Community-based participatory research, Ethnic groups, Health status disparities, Hypertension, Cholesterol

\footnotetext{
*Correspondence: charlotte.jones@ubc.ca

${ }^{\dagger}$ Equal contributors

'Department of Medicine, University of Calgary, Libin Cardiovascular Institute,

TRW Building GE89, 3280 Hospital Drive NW, Calgary, AB, Canada

Full list of author information is available at the end of the article
} 


\section{Background}

While cardiovascular disease (CVD) rates in Canada have decreased substantially in recent decades, significant disparities persist among certain ethnic groups. Along with Aboriginal populations, Canadian South Asians (SAs) experience CVD morbidity and mortality rates 2 to 5 times higher than those of European or Chinese descent [1-5]. Furthermore, both the INTERHEART [6] and a recent study done in Canada [3] suggest that SAs tend to have their first myocardial infarctions about 5 years earlier, on average, relative to the general populations in Canada and elsewhere. These findings mirror those of epidemiological studies from South Africa, Trinidad, Singapore, Fiji, Mauritius, the United States and the UK (reviewed in: $[7,8])$, suggesting that SAs in these countries also carry a disproportionate CVD burden compared with the general population.

Modifiable contributors to this disparity in SA's include the excessively high (3-5 times higher) prevalence of diabetes (including poorly controlled/undetected diabetes), and metabolic syndrome with dyslipidemias including low HDL-cholesterol and high triglycerides relative to the general populations in these countries [1,7,9-13]. Additional significant contributors to these observed disparities include language difficulties, low health literacy, decreased medication adherence, disparate health beliefs, and lack of knowledge, understanding and appreciation of the serious nature of CVD [14-17].

Compared with general public education and social marketing strategies, better health outcomes result from interventions that assess individual risk, encourage personal risk reduction, and put resources in place that create a supportive environment for health and strengthen community action [18-21]. Extensive review of the world literature suggests that community-based participatory research (CBPR) methods that tailor interventions to target barriers specific to a minority group have the greatest potential to reduce disparities in care and outcomes [22-30]. Studies undertaken with participants in their own communities, particularly faith-based interventions involving community health workers or lay health volunteers and the use of educational materials specially adapted for the language, culture and literacy needs of the minority group, showed the greatest promise.

Many exemplar CVD screening and intervention programs originating in Canada, $[31,32]$ the United States [25,28,33-35], the United Kingdom [36-38], India [39] and Pakistan [40] have employed a variety of personnel (peer educators, community health workers, trained barbers, medical/paramedical volunteers) in religious settings $[19,20,41-45]$ to improve cardiovascular health among various minority groups, including African Americans, Hispanics, older adults and low income women. However, short of a similar diabetes program [46], to the best of our knowledge, global CVD risk screening and education programs for SAs that are led by trained lay community volunteers in religious settings have not been implemented in Canada.

SAs constitute the second largest visible minority population in Canada after those with Chinese origins. Calgary, Alberta has the third largest visible minority population in Canada. In 2006, there were over 1.3 million people of SA ethnicity in Canada; over 60,000 of who lived in Calgary [47]. Considering the multiple medical and socio-cultural barriers limiting participation in mainstream programs, accessible and culturally appropriate CVD prevention, screening and risk reduction programs for SAs in Canada are needed.

The objective of this primarily qualitative study was to determine the feasibility of implementing a sustainable, culturally adapted, lay volunteer led community-based CVD risk factor screening program located within places of worship in the SA (originating from Bangladesh, India, Pakistan, and Sri Lanka) community in Calgary, Alberta.

\section{Methods}

\section{The setting}

University of Calgary researchers were approached by SA community leaders in Calgary, Alberta to implement a program similar to two local projects that addressed CVD risk reduction [32,46]. After receiving ethics approval (from the Calgary's Conjoint Health Research Ethics Board) and drawing up a memorandum of understanding, six religious facilities were chosen by these same community leaders as screening locations. Participation was invited by community leaders through weekly announcements at the facilities and notices in local community newsletters, radio and television.

\section{Family physicians}

Family physicians adjacent to the screening venues were invited by letter to a group information and workshop session. Attendees were provided an overview of the study and an update on the Canadian guidelines for hypertension management [48]. Study staff (SM, CAJ, AN) contacted and discussed the program with physicians who did not attend.

\section{Volunteer training}

Forty-nine SA lay community volunteers and allied health care professionals (2 nurses, 2 dieticians, 2 pharmacists and 5 medical students) as identified by community leaders, were provided with a modified version of a validated culturally adapted volunteer training tool [46] to read and attended two 3-hour group training sessions [32]. Volunteers were trained to assess CVD risk and provide advice, education, family physician referral, and referral to local culturally tailored chronic disease management 
(CDM) programs. Volunteers were provided with information on CVD and major risk factors (unhealthy eating, physical inactivity, smoking, excess alcohol consumption, hypertension, dyslipidemia and diabetes). Training in blood pressure (BP) measurement (BpTRU device (model BPM $100^{\circledR}$ :VSM MedTech LTD) and random capillary assessment of total and HDL cholesterol (Cholestech ${ }^{\circledR}$ desk top reflometer, Hayward, CA., USA.) was delivered by a certified trainer from the Calgary Fire Department [49].

Volunteers were trained to assess 10-year total CVD risk using the British Hypertension Society CVD Risk Prediction Chart [50] (http://www.bhsoc.org/Cardiovascular_Risk_Prediction_Chart.stm). As this risk assessment tool underestimates risk among SAs, scores were multiplied by a factor of $1.5[51,52]$. While this risk assessment tool has not been validated in SAs (nor was any other at the time of this study), it was chosen because we were interested in assessing total CVD risk rather than just coronary heart disease risk (as in the Framingham risk tool available at the time of the study [53]) and the simple colored graphics were deemed user friendly for our lay volunteer group.

University of Calgary, Faculty of Medicine experts provided clinical expertise and training; a project coordinator from the community worked with researchers to manage the volunteers and screening sessions.

\section{Baseline screening}

SAs 45 years and older (non-pregnant) presenting for screening were greeted by a project volunteer who confirmed their language of choice and directed then to the appropriate volunteer for eligibility assessment. All program activities were delivered in the participant's language of choice (English, Gujarati, Punjabi, Hindi or the Dari dialect).

After obtaining signed ethics consent, brief questionnaires assessing personal history of CVD, family history of premature CVD, smoking status, and presence of known hypertension, hypercholesterolemia and/or diabetes were administered. Individuals self-reporting a physician diagnosis of or use of medication(s) for high blood pressure, high cholesterol and/or high blood sugar were considered to have hypertension, hypercholesterolemia and/or diabetes, respectively.

Resting BP was measured as per the Canadian guidelines [48] using the automated BPTru ${ }^{\circledR}$ monitor. After five minutes rest, six readings were obtained at one minute intervals. The first reading was discarded and the average of the last five was recorded. Those with elevated systolic BP ( $\geq 140 \mathrm{~mm} \mathrm{Hg}$ or $\geq 130 \mathrm{~mm} \mathrm{Hg}$ among individuals with diabetes) and/or elevated diastolic BP ( $\geq 90 \mathrm{~mm} \mathrm{Hg}$ or $\geq$ $80 \mathrm{~mm} \mathrm{Hg}$ among those with diabetes) or 1 or more CVD risk factor (personal history of CVD, family history of premature CVD, self reported diabetes, hypertension or dyslipidemia, current smoking) were eligible for further study. Eligible participants underwent non-fasting testing for total cholesterol/high density lipoprotein (TC/HDL) ratio and calculation of 10-year total CVD risk. Risk was classified as low-moderate $(\leq 20 \%)$ or high $(>20 \%)$. Those with self-reported CVD or diabetes were automatically classified as high risk. The TC/HDL ratio was considered within target if $<4$ (high risk participants) or $<6$ (lowmoderate risk participants) [54].

Screening results and culturally adapted educational materials [55] detailing CVD risk factors, diet, physical activity, alcohol and smoking were reviewed with and then given to participants. Participants were asked to follow up with their family physicians within one month of screening. Copies of their assessments were faxed to their family physicians, with the suggested option of referring high risk participants to one of three local, culturally sensitive CVD assessment clinics. Low-moderate risk participants were asked to self-refer to the health region's CDM program, consisting of culturally tailored lifestyle counseling and exercise programs. Community leaders insisted that all participants receive the same advice and follow-up recommendations at the same time, precluding any form of randomization (e.g., to immediate vs. delayed intervention).

\section{Follow-up screening}

After 6-13 months (median $=9$ months), participants who completed baseline assessments were contacted by telephone and invited for follow-up. Study funding limited re-screening to the first 100 consecutive participants. They were re-screened exactly as above, and then completed a questionnaire assessing reasons for joining the study; follow-up with family physicians, high risk clinics or CDM programs; satisfaction with the study and suggestions for improvement.

\section{Analysis}

Changes in BP and cholesterol levels (follow-up minus baseline) were calculated and average differences (with 95\% confidence intervals) were estimated using McNemar's test (proportions) and paired t-tests (continuous variables). Change was also assessed by subgroup of interest: gender and self-reported diabetes. All analyses were done using Stata12 (College Stn, TX).

\section{Results}

\section{Baseline screening}

Between May 30 and November 15, 2007, 374 participants attended 12 three hour screening sessions held in 6 different places of worship. Fifty were excluded: $<45$ years of age $(n=5)$, age unknown $(n=5)$, declined BP measurement $(n=19)$, declined further participation after completing health history $(\mathrm{n}=13)$, and currently 
Table 1 Demographic and baseline screening information for SA-CHAMP participants

\begin{tabular}{|c|c|c|c|}
\hline Characteristic & $\begin{array}{c}\text { All } \\
\mathrm{N}=238 \\
\mathrm{n}(\%)\end{array}$ & $\begin{array}{c}\text { Female } \\
\mathrm{N}=122 \\
\mathrm{n}(\%)\end{array}$ & $\begin{array}{c}\text { Male } \\
\mathrm{N}=116 \\
\mathrm{n}(\%)\end{array}$ \\
\hline \multicolumn{4}{|l|}{ Age (years) } \\
\hline $45-59$ & $81(34)$ & $36(30)$ & $45(39)$ \\
\hline $60-79$ & $142(60)$ & $79(65)$ & $63(54)$ \\
\hline 80 or older & $15(6)$ & $7(6)$ & $8(7)$ \\
\hline \multicolumn{4}{|l|}{ Program language of choice } \\
\hline English & $170(71)$ & $82(67)$ & $88(76)$ \\
\hline Gujarati & $41(17)$ & $31(25)$ & $10(9)$ \\
\hline Punjabi & $20(8)$ & $2(2)$ & $18(16)$ \\
\hline Dari & $4(2)$ & $4(3)$ & - \\
\hline Hindi & $3(1)$ & $3(3)$ & - \\
\hline Reported history of CVD ${ }^{*}$ & $24(10)$ & $9(7)$ & $15(13)$ \\
\hline Reported history of stroke/TIA ${ }^{\dagger}$ & $5(2)$ & $1(1)$ & $4(4)$ \\
\hline Parent or sibling with myocardial infarction or stroke before age 60 & $67(28)$ & $37(30)$ & $30(26)$ \\
\hline Current smoker or quit within 3 months & $11(5)$ & - & $11(10)$ \\
\hline Reported history of hypercholesterolemia & $116(49)$ & $54(44)$ & $62(54)$ \\
\hline Reported history of diabetes & $55(23)$ & $28(23)$ & $27(23)$ \\
\hline Reported history of hypertension & $124(52)$ & $70(57)$ & $54(47)$ \\
\hline Elevated systolic and/or diastolic blood pressure ${ }^{\ddagger}$ & $86(36)$ & $47(39)$ & $39(34)$ \\
\hline Controlled TC/HDL ${ }^{\S}$ & $99(42)$ & $73(60)$ & $26(11)$ \\
\hline \multicolumn{4}{|l|}{ Estimated 10-year CVD risk } \\
\hline low-moderate $(<=20 \%)$ & $57(24)$ & $50(41)$ & $7(6)$ \\
\hline \multirow[t]{3}{*}{ high (>20\%) } & $181(76)$ & $72(59)$ & $109(94)$ \\
\hline & mean (SD) & mean (SD) & mean (SD) \\
\hline & range & range & range \\
\hline \multirow[t]{2}{*}{ Systolic blood pressure $(\mathrm{mmHg})$} & $129(18.9)$ & $131(18.8)$ & $127(18.9)$ \\
\hline & $94-185$ & $97-184$ & $94-185$ \\
\hline \multirow[t]{2}{*}{ Diastolic blood pressure $(\mathrm{mmHg})$} & $75(10.4)$ & $74(9.6)$ & $77(11.1)$ \\
\hline & $50-116$ & $53-96$ & $50-116$ \\
\hline \multirow[t]{2}{*}{ Total cholesterol (mmol/L) } & $5.41(1.1)$ & $5.57(1.2)$ & $5.25(1.1)$ \\
\hline & $2.59-9.91$ & $2.85-9.91$ & $2.59-9.37$ \\
\hline \multirow[t]{3}{*}{$\mathrm{HDL}(\mathrm{mmol} / \mathrm{L})$} & $1.12(0.35)$ & $1.23(0.33)$ & $0.99(0.33)$ \\
\hline & $0.39-2.06$ & $0.47-2.06$ & $0.39-2.03$ \\
\hline & $\begin{array}{l}\text { median (IQR } \\
\text { range }\end{array}$ & $\begin{array}{l}\text { median (IQR") } \\
\text { range }\end{array}$ & $\begin{array}{c}\text { median (IQR") } \\
\text { range }\end{array}$ \\
\hline \multirow[t]{2}{*}{$\mathrm{TC} / \mathrm{HDL}$} & $4.7(3.8-6.5)$ & $4.4(3.5-5.4)$ & $5.3(4.2-7.1)$ \\
\hline & $2.4-16$ & $62.4-14.0$ & $2.5-16.7$ \\
\hline
\end{tabular}

* CVD: cardiovascular disease.

† TIA: transient ischemic attack.

F Elevated systolic blood pressure: > $=140 \mathrm{~mm} \mathrm{Hg}$ (non-diabetic) or > $=130 \mathrm{~mm} \mathrm{Hg}$ (diabetic); elevated diastolic blood pressure: >=90 mm $\mathrm{Hg}$ (non-diabetic) or $>=80 \mathrm{~mm} \mathrm{Hg}$ (diabetic).

${ }^{\S}$ Controlled TC/HDL: $<4$ for high risk participants; $<6$ for low-moderate risk participants.

"IQR: interquartile range. 
under the care of a cardiac specialist $(\mathrm{n}=8)$. Two hundred thirty eight were eligible for complete screening.

Men and women were equally represented and had similar age distributions (Table 1). The majority selected English as their language of choice. Thirty-six percent had elevated BP, 58\% had elevated TC/HDL ratios, 23\% reported diabetes and $76 \%$ were at high risk for CVD. Compared with women, men were significantly more likely to have elevated TC/HDL ratios (78\% vs. $40 \%)$ and to be at high risk for CVD ( $94 \%$ vs. 59\%). Those with diabetes were more likely than non-diabetics to have hypertension (measured plus reported) and elevated TC/ HDL ratios (data not shown).

\section{Follow-up screening}

Of the 100 individuals who completed follow-up, 1 did not meet the original study eligibility criteria and was excluded. While comparable on all other variables (data not shown), individuals presenting for follow-up had a higher median TC/HDL ratio when compared with all who presented for baseline screening (5.2 vs. 4.7).

Mean systolic and diastolic BP did not change from baseline to follow-up (mean differences: $-0.3 \mathrm{~mm} \mathrm{Hg}$ and $-0.5 \mathrm{~mm} \mathrm{Hg}$, respectively) and remained elevated in $35 \%$ at follow-up (Table 2). The average total cholesterol decreased significantly overall and among all subgroups examined while the average HDL increased overall and among all subgroups examined with the exception of those with diabetes in whom the average HDL did not change. The average TC/HDL ratio decreased significantly overall and among all subgroups examined. While a significant increase in the proportion of individuals with TC/HDL ratios within target was noted overall, the improvement appeared to be limited to men (18\%) and those without diabetes (14\%) (Table 2).

All 99 participants completed the evaluation questionnaire. Reasons for taking part in the study included interest in knowing their BP and cholesterol (35\%), desire for follow-up of a pre-existing health concern (31\%) or to obtain more information about cardiovascular health (22\%), curiosity (18\%) and being asked to attend by someone else (18\%). Fifty-eight percent reported being somewhat or a lot worried by the information that they received. Most (82\%) had visited their family physicians to discuss their results, with no difference by age, sex, or CVD risk category. Among these, 66\% discussed their CVD risk profiles and $22 \%$ had medication changes initiated. Specialty clinic referrals were made for $31 \%$ of high risk participants; $84 \%$ attended, $10 \%$ did not, and $6 \%$ were awaiting appointments. A search of the CDM program registry revealed that only 2 of the 57 low-moderate risk participants had self-referred to the available programs. Time constraints $(44 \%)$ and lack of perceived need (9\%) were the two most commonly cited reasons for non-attendance.
While all participants reported being very satisfied (80\%) or satisfied $(20 \%)$ with the project, it was suggested that screening sessions and CDM programs be made more accessible by: delivering programs during evening hours or weekends and at more sites; providing transportation; offering multilingual programs or translation assistance; reducing screening wait times and increasing the numbers of project staff.

Since completion of this program, and based on our participants' suggestions, local CDM programs are now being offered at more sites and with extended hours of operation. Furthermore, CVD risk screenings have continued in many of the participating SA communities and have been refined based on the suggestions made by our SA CHAMP participants. A community volunteer maintains the program and has trained several other volunteers. With the Public Health Agency of Canada's support, similar programs piloting screening coupled with "health buddy" follow-up are ongoing in Calgary and five other cities across Canada.

\section{Discussion}

The SA-CHAMP is unique in that it demonstrated the feasibility of using trained lay community volunteers to run a sustainable, culturally adapted opportunistic CVD risk factor screening project in places of worship within the SA community in Calgary, Alberta, Canada. Furthermore, despite this being a pilot trial, modest but significant improvement in cholesterol measures were noted. Much of the success and acceptability of this program is a reflection of the high level of community engagement and volunteer participation throughout all stages of the program including the design, implementation and evaluation; key factors in the well accepted CBPR approach to reducing health disparities in minority populations [22]. The degree of community "buy-in" or ownership of the program and the strong commitment of the lay community members that has led to the dissemination of the program beyond its original setting to SA communities across Canada also makes this program unique in Canada.

Places of worship play a strong cultural and social role in many communities across the world, and are a place where community members come together. They have been shown to provide a particularly relevant and culturally comfortable setting for health-related interventions $[19,43,44,56,57]$. The bulk of this evidence is derived from studies done in the United States within African American and Hispanic communities. However, there are two recent studies other than ours suggesting the feasibility of using places of worship in SA communities to identify individuals with CVD risk factors. Davachi et al. [46] demonstrated that when diabetes screening sessions for those without known diabetes were held in the context of religious gatherings in temples and mosques in Calgary, Alberta, it 
Table 2 Change in blood pressure and TC/HDL among SA-CHAMP participants who completed follow-up

\begin{tabular}{|c|c|c|c|c|c|}
\hline Characteristic & $n$ & $\begin{array}{c}\text { Baseline } \\
\text { proportion }\end{array}$ & $\begin{array}{l}\text { Follow-up } \\
\text { proportion }\end{array}$ & $\begin{array}{l}\text { Mean difference } \\
(95 \% \text { C.I. })\end{array}$ & p-value \\
\hline \multicolumn{6}{|c|}{$\begin{array}{l}\text { Elevated systolic and/or } \\
\text { diastolic blood pressure }\end{array}$} \\
\hline All & 99 & 0.39 & 0.35 & $-0.04(-0.14$ to 0.06$)$ & 0.524 \\
\hline Men & 52 & 0.38 & 0.33 & $-0.06(-0.21$ to 0.10$)$ & 0.581 \\
\hline Women & 47 & 0.40 & 0.38 & $-0.02(-0.17$ to 0.12$)$ & 1.000 \\
\hline Diabetics & 27 & 0.52 & 0.56 & $0.04(-0.22$ to 0.30$)$ & 0.739 \\
\hline Non-diabetics & 72 & 0.35 & 0.28 & $-0.07(-0.18$ to 0.04$)$ & 0.267 \\
\hline \multicolumn{6}{|l|}{ Controlled TC/HDL ${ }^{\S}$} \\
\hline All & 98 & 0.34 & 0.46 & 0.12 (0.01 to 0.23 ) & 0.029 \\
\hline Men & 51 & 0.20 & 0.37 & 0.18 (0.03 to 0.33 ) & 0.023 \\
\hline Women & 47 & 0.49 & 0.55 & $0.06(-0.10$ to 0.23$)$ & 0.581 \\
\hline Diabetics & 27 & 0.30 & 0.37 & $0.07(-0.14$ to 0.29$)$ & 0.688 \\
\hline \multirow[t]{2}{*}{ Non-Diabetics } & 71 & 0.35 & 0.49 & 0.14 (0.01 to 0.27$)$ & 0.041 \\
\hline & $\mathrm{n}$ & $\begin{array}{l}\text { Mean at } \\
\text { baseline }\end{array}$ & $\begin{array}{c}\text { Mean at } \\
\text { follow-up }\end{array}$ & $\begin{array}{c}\text { Mean paired difference } \\
(95 \% \text { C.I.) }\end{array}$ & p-value \\
\hline \multicolumn{6}{|l|}{ Total Cholesterol } \\
\hline All & 99 & 5.56 & 5.04 & $-0.52(-0.71$ to -0.34$)$ & $<0.001$ \\
\hline Men & 52 & 5.34 & 4.81 & $-0.53(-0.81$ to -0.24$)$ & $<0.001$ \\
\hline Women & 47 & 5.81 & 5.30 & $-0.52(-0.76$ to -0.28$)$ & $<0.001$ \\
\hline Diabetics & 27 & 5.45 & 5.13 & $-0.32(-0.63$ to -0.01$)$ & 0.043 \\
\hline Non-Diabetics & 72 & 5.61 & 5.01 & $-0.60(-0.83$ to -0.37$)$ & $<0.001$ \\
\hline \multicolumn{6}{|l|}{ HDL Cholesterol } \\
\hline All & 98 & 1.08 & 1.15 & 0.07 (0.03 to 0.11$)$ & 0.002 \\
\hline Men & 51 & 0.96 & 1.03 & 0.06 (0.00 to 0.12$)$ & 0.038 \\
\hline Women & 47 & 1.21 & 1.29 & 0.08 (0.01 to 0.14$)$ & 0.029 \\
\hline Diabetics & 27 & 1.08 & 1.11 & 0.04 (0.06 to 0.13 ) & 0.456 \\
\hline Non-Diabetics & 71 & 1.09 & 1.17 & 0.08 (0.03 to 0.13 ) & 0.002 \\
\hline \multicolumn{6}{|l|}{$\mathrm{TC} / \mathrm{HDL}$} \\
\hline All & 98 & 5.80 & 4.76 & $-1.04(-1.41$ to -0.68$)$ & $<0.001$ \\
\hline Men & 51 & 6.34 & 5.03 & $-1.31(-1.92$ to -0.69$)$ & $<0.001$ \\
\hline Women & 47 & 5.21 & 4.46 & $-0.76(-1.13$ to -0.38$)$ & $<0.001$ \\
\hline Diabetics & 27 & 5.85 & 4.98 & $-0.87(-1.70$ to -0.04$)$ & 0.041 \\
\hline Non-Diabetics & 71 & 5.78 & 4.67 & $-1.11(-1.51$ to -0.71$)$ & $<0.001$ \\
\hline
\end{tabular}

* Elevated systolic blood pressure: > $=140 \mathrm{~mm} \mathrm{Hg}$ (non-diabetics) or > = $130 \mathrm{~mm} \mathrm{Hg}$ (diabetics); elevated diastolic blood pressure: > = $90 \mathrm{~mm} \mathrm{Hg}$ (non-diabetics) or $>=80 \mathrm{~mm} \mathrm{Hg}$ (diabetics).

${ }^{\S}$ Controlled TC/HDL: $<4$ for high risk participants; $<6$ for low-moderate risk participants.

was highly acceptable to community members and is reflected in the high participation rate (922 screened in 14 four hour screening sessions). Similarly, Rao et al. [45] screened for CVD risk in two Hindu temples in London, England. In this study medical/paramedical community members were able to screen 434 self-selected participants in 9 six-hour sessions. This group is currently carrying out a qualitative assessment of the acceptability of the program among staff and participating community members.
Use of trained lay health workers as part of the healthcare team in community-based program settings is recognized as a way to improve access and the health of underserved populations [22]. Community members trained as peer health advisors, particularly those who are members of the target community, may play a significant role in addressing cardiovascular risk factors because of their connectedness to individuals and communities, as well as their understanding of cultural and contextual issues $[28,58,59]$. A noteworthy example is the recent 
study looking at the effectieveness of barbers who were trained and paid to become health educators, monitor BP, and promote physician referral for patrons of local African-American-owned barbershops in Dallas County, Texas, USA. While improvement in the primary outcome of hypertension among African-American male patrons was modest (8.8\%, 95\% confidence interval: $0.8 \%-16.9 \%)$, 98\% of participants and all 29 participating barbers reported that they would like the program continued indefinitely.

Until recently, there has been a paucity of literature on the effectiveness of trained lay community members as volunteers, specifically in the context of community-based CVD risk factor screening and improved CVD outcomes. In a cluster randomized controlled trial of 39 communities in Ontario, Canada [31], volunteer lay seniors were trained to perform BP and cardiovascular risk assessment on other seniors invited by their physicians to attend pharmacybased screening clinics. Within one year of the screening program, a 9\% relative reduction in CVD-related hospital admissions was noted, translating to 3.02 fewer hypertension-related hospitalizations per 1000 people aged 65 and older in the intervention communities. Our study and that of Davachi et al. [46] differ from the Kaczorowski study in that they were both adapted for the SA community and as such, the lay trained volunteers were SA and the screenings took place in religious facilities rather than community pharmacies. The use of trained lay community volunteers in this setting shows promise and our study helps to support the feasibility of implementing a similar larger RCT in SA communities to evaluate whether such an intervention can reduce CVD in this group.

The value (in terms of identifying at-risk individuals that would benefit from intervention) of opportunistic CVD risk screening in SA places of worship has not been well described. Using a methodology similar to ours, Davachi et al. [46] opportunistically screened adult non-diabetic SA for diabetes in places of worship, and observed very high rates of obesity (67\%), family history of diabetes (43\%) and results suggestive of potential glucose intolerance (36\%). Despite excluding of those with self reported CVD, hypertension, diabetes or use of lipid therapy, [45] Rao et al. found that $52 \%$ of participants had hypertension, $75 \%$ had central obesity, $10 \%$ had TC/HDL ratios $>6$, and $15 \%$ were assessed as high risk using the QRISK2 model for 10-year CVD risk. The higher prevalence of both poorly controlled risk factors and 10-year CVD risk among participants in our study are consistent with their higher average age and their relatively high prevalence of self-reported CVD (10\%), diabetes (23\%), hypertension (52\%) and dyslipidemia (49\%). While these three studies are not directly comparable given the variable inclusion criteria, screening techniques, ages and ethnic groups represented, a high prevalence of modifiable, poorly controlled CVD risk in the SAs that self-presented for screening was a consistent finding. The majority of participants were at moderate to high risk for CVD and therefore represented an ideal target group for improving awareness and risk factor management. Further, participants in our study were satisfied with the program and barriers to healthcare provider access did not appear to be a problem. Overall, these three studies provide support for the feasibility, acceptability and value of screening SA adults for CVD risk factors in places of worship.

Our study has limitations. Participants self-selected for study and it is not known if participants in this study are representative of the SA community at large. Self-selected participants may have been more motivated, particularly those who returned for follow-up, which could partially explain the observed reduction in TC/HDL ratios and high rates of follow-up with family physicians. Our study design (single group, before-and-after) was also vulnerable to regression to the mean. While significant TC/HDL ratio reductions were still observed when the analysis was limited to those without outlying values at baseline, random variation, rather than follow-up care, may explain some of the observed improvements in lipid control. Furthermore, while there are small variations in lipid measures between the Cholestech ${ }^{\circledR}$ desk top reflometer and full laboratorybased lipid profiles, especially in the case of elevated triglycerides, Cholestech ${ }^{\circledR}$ measures are considered acceptable under these circumstances [60]. However, we cannot rule out such variability as contributing a measure of uncertainty to our cholesterol measures. Additionally, relying on a single measure of blood pressure at baseline may have led to an overestimation of the prevalence of hypertension among those screened.

With respect to data collection, we had no way of validating self-reported information. The validity of self-report of CVD risk factors and follow-up behavior in the context of reporting such sensitive information to a community volunteer possibly known to the participant is an interesting area for future study. Further, the study protocol depended to a great extent on trained lay volunteers and may not be generalizable to all SA communities where volunteerism is not as prevalent.

Given that this study was primarily qualitative, and that no a priori power/sample size calculation was performed, the significance of the pre-post changes (or lack thereof) in clinical parameters should not be over-interpreted. These analyses were conducted on an exploratory basis only. The variability in the studies measures will be used to determine a sample size for a future, larger study.

Finally, while modified versions of the program have been initiated in Calgary and 5 other cities in Canada, it is not yet known if the programs will prove feasible on a large and sustainable scale and demonstrate effectiveness within the target population. 


\section{Conclusions}

SA-CHAMP demonstrated the feasibility of implementing a culturally adapted, sustainable community-based CVD risk factor screening program in the SA community in Calgary, Alberta, Canada. SA-CHAMP identified a high risk cohort amenable to intervention. Participants' input has helped to refine the next iteration of screening programs and has helped change policy for the delivery of local CDM programs. Further research is needed to determine the content and delivery of sustainable intervention programs that will successfully reduce CVD risk factors and disease risk in this population.

\section{Abbreviations}

SA-CHAMP: South Asian Cardiovascular Health Assessment and Management Program; TC/HDL: Total Cholesterol/High Density Lipoprotein;

CVD: Cardiovascular Disease; BP: Blood Pressure.

\section{Competing interests}

The authors' declare that they have no competing interests.

\section{Authors' contributions}

CAJ conceived of the study, participated in its design and coordination and drafted the manuscript. LMR performed the statistical analysis and participated in drafting the manuscript. All authors read and approved the final manuscript.

\section{Acknowledgements}

The authors would like to acknowledge Dennis Rabel of the Calgary Fire Department blood pressure screening program, Calgary, Alberta and Grace Wang who provided intial guidance with statistical analysis.

\section{Author details}

${ }^{1}$ Department of Medicine, University of Calgary, Libin Cardiovascular Institute, TRW Building GE89, 3280 Hospital Drive NW, Calgary, AB, Canada. ${ }^{2}$ Libin Cardiovascular Institute, Calgary, $A B$, Canada. ${ }^{3}$ University of Calgary, Calgary, $A B$, Canada. ${ }^{4}$ Alberta Health Services, Calgary, $A B$, Canada. ${ }^{5}$ Faculty of Nursing, University of Calgary, Calgary, $A B$, Canada.

Received: 28 May 2012 Accepted: 19 February 2013

Published: 21 February 2013

\section{References}

1. Anand SS, Yusuf S, Vuksan V, Devanesen S, Teo KK, Montague PA, Kelemen $L$, Yi C, Lonn E, Gerstein H, et al: Differences in risk factors, atherosclerosis, and cardiovascular disease between ethnic groups in Canada: the Study of Health Assessment and Risk In Ethnic groups (SHARE). Lancet 2000, 356(9226):279-284.

2. Anand SS, Yusuf $S$, Jacobs R, Davis AD, Yi Q, Gerstein $H$, Montague PA, Lonn E: Risk factors, atherosclerosis, and cardiovascular disease among Aboriginal people in Canada: the Study Of Health Assessment and Risk Evaluation In Aboriginal Peoples (SHARE-AP). Lancet 2001, 358(9288): 1147-1153.

3. Nijjar AP, Wang H, Quan H, Khan NA: Ethnic and sex differences in the incidence of hospitalized acute myocardial infarction: British Columbia, Canada 1995-2002. BMC Cardiovasc Disord 2010, 10:38.

4. Sheth T, Nair C, Nargundkar M, Anand S, Yusuf S: Cardiovascular and cancer mortality among Canadians of European, South Asian and Chinese origin from, 1979 to 1993: an analysis of 1.2 million deaths. CMAJ 1999, 161(2):132-138.

5. Wilkins R, Tjepkema M, Mustard C, Choiniere R: The Canadian census mortality follow-up study, 1991 through 2001. In Health Rep. vol. 19; 2008:25-43.

6. Joshi P, Islam S, Pais P, Reddy S, Dorairaj P, Kazmi K, Pandey MR, Haque S, Mendis S, Rangarajan S, et al: Risk factors for early myocardial infarction in South Asians compared with individuals in other countries. JAMA 2007, 297(3):286-294.
7. Bainey KR, Jugdutt BI: Increased burden of coronary artery disease in South-Asians living in North America. Need for an aggressive management algorithm. Atherosclerosis 2009, 204(1):1-10.

8. Kurian AK, Cardarelli KM: Racial and ethnic differences in cardiovascular disease risk factors: a systematic review. Ethn Dis 2007, 17(1):143-152.

9. Meadows TA, Bhatt DL, Cannon CP, Gersh BJ, Rother J, Goto S, Liau CS, Wilson PW, Salette G, Smith SC, et al: Ethnic differences in cardiovascular risks and mortality in atherothrombotic disease: insights from the Reduction of Atherothrombosis for Continued Health (REACH) registry. Mayo Clin Proc 2011, 86(10):960-967.

10. Leenen FH, Dumais J, Mclnnis NH, Turton P, Stratychuk L, Nemeth K, LumKwong MM, Fodor G: Results of the Ontario survey on the prevalence and control of hypertension. CMAJ 2008, 178(11):1441-1449.

11. Nair M, Prabhakaran D: Why do South Asians have high risk for CAD? Global Heart 2012, 8:1-8.

12. Ramaraj R, Chellappa P: Cardiovascular risk in South Asians. Postgrad Med J 2008, 84(996):518-523.

13. Bhatnagar D, Anand IS, Durrington PN, Patel DJ, Wander GS, Mackness MI, Creed F, Tomenson B, Chandrashekhar Y, Winterbotham M, et al: Coronary risk factors in people from the Indian subcontinent living in west London and their siblings in India. Lancet 1995, 345(8947):405-409.

14. King KM, LeBlanc P, Sanguins J, Mather C: Gender-based challenges faced by older Sikh women as immigrants: recognizing and acting on the risk of coronary artery disease. Can J Nurs Res 2006, 38(1):16-40.

15. Lai DW, Surood S: Types and factor structure of barriers to utilization of health services among aging South Asians in Calgary, Canada. Can J Aging 2010, 29(2):249-258.

16. Lai EJ, Grubisic M, Palepu A, Quan H, King KM, Khan NA: Cardiac medication prescribing and adherence after acute myocardial infarction in Chinese and South Asian Canadian patients. BMC Cardiovasc Disord 2011, 11:56.

17. Rankin J, Bhopal R: Understanding of heart disease and diabetes in a South Asian community: cross-sectional study testing the 'snowball' sample method. Public Health 2001, 115(4):253-260.

18. Glazier RH, Bajcar J, Kennie NR, Willson K: A systematic review of interventions to improve diabetes care in socially disadvantaged populations. Diabetes Care 2006, 29(7):1675-1688.

19. Dodani S: Community-based participatory research approaches for hypertension control and prevention in churches. Int J Hypertens 2011, 2011:273120.

20. Parrill R, Kennedy BR: Partnerships for health in the African American community: moving toward community-based participatory research. J Cult Divers 2011, 18(4):150-154.

21. Thurston WE, Vollman AR, Wilson DR, Mackean G, Felix R, Wright MF: Development and testing of a framework for assessing the effectiveness of health promotion. Soz Praventivmed 2003, 48(5):301-316.

22. De Las Nueces D, Hacker K, Digirolamo A, Hicks LS: A systematic review of community-based participatory research to enhance clinical trials in racial and ethnic minority groups. Health Serv Res 2012, 47(3):1363-1368.

23. Davis AM, Vinci LM, Okwuosa TM, Chase AR, Huang ES: Cardiovascular health disparities: a systematic review of health care interventions. Med Care Res Rev 2007, 64(5 Suppl):29S-100S.

24. Chin MH, Walters AE, Cook SC, Huang ES: Interventions to reduce racial and ethnic disparities in health care. Med Care Res Rev 2007, 64(5 Suppl):7S-28S.

25. Crook ED, Bryan NB, Hanks R, Slagle ML, Morris CG, Ross MC, Torres HM, Williams RC, Voelkel C, Walker $\mathrm{S}$, et al: A review of interventions to reduce health disparities in cardiovascular disease in african americans. Ethn Dis 2009, 19(2):204-208.

26. Peek ME, Cargill A, Huang ES: Diabetes health disparities: a systematic review of health care interventions. Med Care Res Rev 2007, 64(5 Suppl):101S-156S.

27. Quinones AR, O'Neil M, Saha S, Freeman M, Henry S, Kansagara D: Interventions to Improve Minority Health Care and Reduce Racial and Ethnic Disparities Portland OR: VA-ESP Department of Veterans Affairs; 2011. Project \#05-225.

28. Fleury J, Keller C, Perez A, Lee SM: The role of lay health advisors in cardiovascular risk reduction: a review. Am J Community Psychol 2009, 44(1-2):28-42.

29. Lewin SA, Dick J, Pond P, Zwarenstein M, Aja G, van Wyk B, BoschCapblanch X, Patrick M: Lay health workers in primary and community health care. Cochrane Database Syst Rev 2005, 1:CD004015. 
30. Netto G, Bhopal R, Khatoon J, Lederle N, Jackson A: Health promotion and prevention interventions in Pakistani, Chinese and Indian communities related to CVD and cancer: a review of the published evidence in the UK, other parts of Europe and the United States. In Health Scotland. United Kingdom: School of the Built Environment Heriot Watt University Edinburgh EH14 1AS; 2008.

31. Kaczorowski J, Chambers LW, Dolovich L, Paterson JM, Karwalajtys T, Gierman T, Farrell B, McDonough B, Thabane L, Tu K, et al: Improving cardiovascular health at population level: 39 community cluster randomized trial of Cardiovascular Health Awareness Program (CHAP). BMJ 2011, 342:d442.

32. Jones C, Simpson SH, Mitchell D, Haggarty S, Campbell N, Then K, Lewanczuk RZ, Sebaldt RJ, Farrell B, Dolovitch L, et al: Enhancing hypertension awareness and management in the elderly: lessons learned from the Airdrie Community Hypertension Awareness and Management Program (A-CHAMP). Can J Cardiol 2008, 24(7):561-567.

33. Victor RG, Ravenell JE, Freeman A, Leonard D, Bhat DG, Shafiq M, Knowles P, Storm JS, Adhikari E, Bibbins-Domingo K, et al: Effectiveness of a barber-based intervention for improving hypertension control in black men: the BARBER-1 study: a cluster randomized trial. Arch Intern Med 2011, 171(4):342-350.

34. Rhodes SD, Foley KL, Zometa CS, Bloom FR: Lay health advisor interventions among Hispanics/Latinos: a qualitative systematic review. Am J Prev Med 2007, 33(5):418-427.

35. Lewin S, Munabi-Babigumira S, Glenton C, Daniels K, Bosch-Capblanch $X$, van Wyk BE, Odgaard-Jensen J, Johansen M, Aja GN, Zwarenstein M et al: Lay health workers in primary and community health care for maternal and child health and the management of infectious diseases. Cochrane Database Syst Rev 2010, 3:CD004015.

36. Farooqi A, Bhavsar M: Project Dil: a coordinated primary care and community health promotion programme for reducing risk factors of coronary heart disease amongst the South Asian community of Leicester-experiences and evaluation of the project. Ethn Health 2001, 6(3-4):265-270.

37. Griffiths C, Foster G, Ramsay J, Eldridge S, Taylor S: How effective are expert patient (lay led) education programmes for chronic disease? BMJ 2007, 334(7606):1254-1256.

38. Webb DR, Khunti K, Gray LJ, Srinivasan BT, Farooqi A, Wareham N, Griffin SC, Davies MJ: Intensive multifactorial intervention improves modeled coronary heart disease risk in screen-detected type 2 diabetes mellitus: a cluster randomized controlled trial. Diabet Med 2012, 29(4):531-540.

39. Kar SS, Thakur JS, Jain S, Kumar R: Cardiovascular disease risk management in a primary health care setting of North India. Indian Heart J 2008, 60(1):19-25.

40. Jafar TH, Hatcher J, Poulter N, Islam M, Hashmi S, Qadri Z, Bux R, Khan A, Jafary FH, Hameed A, et al: Community-based interventions to promote blood pressure control in a developing country: a cluster randomized trial. Ann Intern Med 2009, 151(9):593-601.

41. Carson JA, Michalsky L, Latson B, Banks K, Tong L, Gimpel N, Lee JJ, Dehaven MJ: The cardiovascular health of urban African Americans: dietrelated results from the genes, Nutrition, Exercise, Wellness, and Spiritual Growth (GoodNEWS) trial. J Acad Nutr Diet 2012, 112(11):1852-1858.

42. Hosler AS, Berberian EL, Spence MM, Hoffman DP: Outcome and cost of a statewide diabetes screening and awareness initiative in New york. J Public Health Manag Pract 2005, 11(1):59-64.

43. Davis DS, Goldmon MV, Coker-Appiah DS: Using a community-based participatory research approach to develop a faith-based obesity intervention for African American children. Health Promot Pract 2011 12(6):811-822

44. Yanek LR, Becker DM, Moy TF, Gittelsohn J, Koffman DM: Project Joy: faith based cardiovascular health promotion for African American women. Public Health Rep 2001, 116(Suppl 1):68-81.

45. Rao N, Eastwood SV, Jain A, Shah M, Leurent B, Harvey D, Robertson L, Walters K, Persaud JW, Mikhailidis DP, et al: Cardiovascular risk assessment of South Asians in a religious setting: a feasibility study. Int J Clin Pract 2012, 66(3):262-269.

46. Davachi S, Flynn M, Edwards A: A health region/community partnership for type 2 diabetes risk factor screening in Indo-Asian communities. Can J Diabetes 2005, 29(2):87-94.

47. Statistics Canada: Ethnic origin for the population of Canada, provinces, territories, census metropolitan areas and census agglomerations, 2006 census; 2006. http://www.statcan.gc.ca.
48. Padwal RS, Hemmelgarn BR, McAlister FA, McKay DW, Grover S, Wilson T, Penner B, Burgess E, Bolli P, Hill M, et al: The 2007 Canadian Hypertension Education Program recommendations for the management of hypertension: part 1- blood pressure measurement, diagnosis and assessment of risk. Can J Cardiol 2007, 23(7):529-538.

49. Campbell NR, Jeffrey P, Kiss K, Jones C, Anton AR: Building capacity for awareness and risk factor identification in the community: the blood pressure assessment program of the Calgary Fire Department. Can J Cardiol 2001, 17(12):1275-1279.

50. JBS 2: Joint British Societies' guidelines on prevention of cardiovascular disease in clinical practice. Heart 2005, 91 Suppl 5:v1-52.

51. Aarabi M, Jackson PR: Predicting coronary risk in UK South Asians: an adjustment method for Framingham-based tools. Eur J Cardiovasc Prev Rehabil 2005, 12(1):46-51

52. Mathews G, Alexander J, Rahemtulla T, Bhopal R: Impact of a cardiovascular risk control project for South Asians (Khush Dil) on motivation, behaviour, obesity, blood pressure and lipids. J Public Health (Oxf) 2007, 29(4):388-397.

53. D'Agostino RB Sr, Grundy S, Sullivan LM, Wilson P: Validation of the Framingham coronary heart disease prediction scores: results of a multiple ethnic groups investigation. JAMA 2001, 286(2):180-187.

54. McPherson R, Frohlich J, Fodor G, Genest J, Canadian Cardiovascular S: Canadian Cardiovascular Society position statement-recommendations for the diagnosis and treatment of dyslipidemia and prevention of cardiovascular disease. Can J Cardio/ 2006, 22(11):913-927.

55. Jones CA, Mawani S, King KM, Allu SO, Smith M, Mohan S, Campbell NR: Tackling health literacy: adaptation of public hypertension educational materials for an Indo-Asian population in Canada. BMC Public Health 2011, 11:24.

56. DeHaven MJ, Ramos-Roman MA, Gimpel N, Carson J, DeLemos J, Pickens S, Simmons C, Powell-Wiley T, Banks-Richard K, Shuval K, et al: The GoodNEWS (genes, nutrition, exercise, wellness, and spiritual growth) trial: a community-based participatory research (CBPR) trial with AfricanAmerican church congregations for reducing cardiovascular disease risk factors--recruitment, measurement, and randomization. Contemp Clin Trials 2011, 32(5):630-640.

57. Wilcox S, Laken M, Parrott AW, Condrasky M, Saunders R, Addy CL, Evans R, Baruth M, Samuel M: The faith, activity, and nutrition (FAN) program: design of a participatory research intervention to increase physical activity and improve dietary habits in African American churches. Contemp Clin Trials 2010, 31(4):323-335.

58. Foster G, Taylor SJ, Eldridge SE, Ramsay J, Griffiths CJ: Self-management education programmes by lay leaders for people with chronic conditions. Cochrane Database Syst Rev 2007, 4:CD005108.

59. Glenton C, Scheel IB, Lewin S, Swingler GH: Can lay health workers increase the uptake of childhood immunization? Systematic review and typology. Trop Med Int Health 2011, 16(9):1044-1053.

60. Jain A, Persaud JW, Rao N, Harvey D, Robertson L, Nirmal L, Nirmal D, Thomas M, Mikhailidis DP, Nair DR: Point of care testing is appropriate for national health service health check. Ann Clin Biochem 2011, 48(Pt 2):159-165.

doi:10.1186/1471-2458-13-160

Cite this article as: Jones et al:: Feasibility of community-based screening for cardiovascular disease risk in an ethnic community: the South Asian Cardiovascular Health Assessment and Management Program (SA-CHAMP). BMC Public Health 2013 13:160. 